\title{
ReSEARChArticle
}

\section{Studies on genetic variability for yield and yield traits in rice (Oryza sativa L.)}

Ashish Goswami

\section{SUMMARY}

Genetic variability in any crop is pre-requisite for selection of superior genotypes over the existing cultivars. In the Asia and Pacific region, rice is the main staple food and the most important source of employment and income for rural people. Knowledge of variability and heritability of yield and its contributing traits helps in the selection of appropriate strategy for a breeding programme for evolving superior varieties. Therefore, the present investigation was conducted to assess the variability present in $F_{1}$ hybrids and their parents for yield and yield contributing traits. In present study, Variance analysis for all the characters revealed significant variation among the genotypes studied, indicating the existence of sufficient amount of variability. The GCV, PCV, broad sense heritability and genetic advances as percent of mean suggested number of panicle bearing tillers per plant, spikelets fertility, plant height, panicle length, number of spikelets per panicle, test weight, and grain yield per plant were important contributing traits and selection based on these traits would be most effective.

Key Words : Rice, Heritability, Variability, Genetic advance

How to cite this article : Goswami, Ashish (2018). Studies on genetic variability for yield and yield traits in rice (Oryza sativa L.). Internat. J. Plant Sci., 13 (1): 188-191, DOI: 10.15740/HAS/IJPS/13.1/188-191.

Article chronicle : Received : 06.10.2017; Revised : 12.12.2017; Accepted : 26.12.2017

\footnotetext{
Author to be contacted :

Ashish Goswami, Department of Agriculture Botany, Udai Pratap

Autonomous College, Varanasi (U.P.) India

Email : ashishgoswamiupc2013@gmail.com
} 